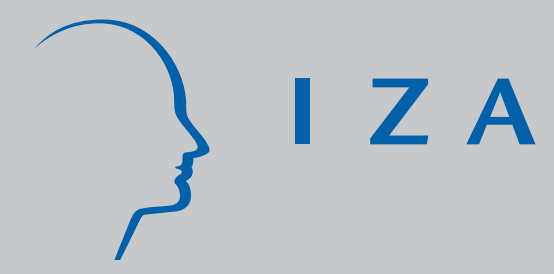

IZA DP No. 1408

On the Political Economy of Social Security and Public Education

Panu Poutvaara

November 2004 


\title{
On the Political Economy of Social Security and Public Education
}

\author{
Panu Poutvaara \\ CEBR, CESifo \\ and IZA Bonn
}

\section{Discussion Paper No. 1408 \\ November 2004}

\author{
IZA \\ P.O. Box 7240 \\ 53072 Bonn \\ Germany \\ Phone: +49-228-3894-0 \\ Fax: +49-228-3894-180 \\ Email: iza@iza.org
}

\begin{abstract}
Any opinions expressed here are those of the author(s) and not those of the institute. Research disseminated by IZA may include views on policy, but the institute itself takes no institutional policy positions.

The Institute for the Study of Labor (IZA) in Bonn is a local and virtual international research center and a place of communication between science, politics and business. IZA is an independent nonprofit company supported by Deutsche Post World Net. The center is associated with the University of Bonn and offers a stimulating research environment through its research networks, research support, and visitors and doctoral programs. IZA engages in (i) original and internationally competitive research in all fields of labor economics, (ii) development of policy concepts, and (iii) dissemination of research results and concepts to the interested public.
\end{abstract}

IZA Discussion Papers often represent preliminary work and are circulated to encourage discussion. Citation of such a paper should account for its provisional character. A revised version may be available directly from the author. 
IZA Discussion Paper No. 1408

November 2004

\section{ABSTRACT \\ On the Political Economy of Social Security and Public Education}

This paper analyzes simultaneous voting on the wage tax rate and investment in public education with three overlapping generations and productivity differences inside each cohort. Wage tax revenue finances public education and social security benefits. The presence of productivity differences introduces a time-consistency problem with repeated voting. This can be solved by trigger strategies which do not punish upward deviations in the wage tax rate. If there are multiple equilibria, then higher tax rates are associated with more education. Surprisingly, the median voter may be a young citizen even when cohorts are of the same size.

JEL Classification: H52, H55, D72

Keywords: $\quad$ social security, public education, voting

Panu Poutvaara

CEBR

Copenhagen Business School

Porcelaenshaven, Bldg 65

DK-2000 Frederiksberg

Denmark

Email: panu.poutvaara@cebr.dk 


\section{Introduction}

An important and often overlooked aspect in reforming social security are political linkages between different public expenditures. Education and social security are amongst the most important public expenditures in most developed countries. The education system to a large extent determines future human capital and is therefore crucial to productive capacity. Social security benefits are a major form of redistribution in most countries, taking in average 8.8 percent of the GDP in the member states of the European Union in 2001 (OECD, 2004a). At the same time, public expenditures on higher education took in average 1.4 percent of GDP (OECD, 2004b). These systems interact in individual and political decision-making, as redistribution through social security gives lower-productivity individuals a claim on the future productivity of high-productivity individuals. Boldrin and Montes (2002) formalize public education and pay-as-you-go social security as two parts of an intergenerational contract. They assume identical voters inside each cohort and show that public education can be maintained by linking it into a sufficiently large social security system. Rangel (2003) characterizes an implicit intergenerational contract on the provision of social security and goods benefiting younger generations, like education and environment, also focusing on the case of identical individuals.

In the presence of productivity differences, an implicit intergenerational contract on financing higher education may suffer from time-consistency problem. Young highproductivity citizens may be prime beneficiaries from an intergenerational contract linking public education and social security benefits, but lose their interest to support it after completing their education and starting to work and pay taxes. Nonetheless, public education and social security have emerged and persisted in the political process in all member states of the European Union. This paper suggests a median voter model that explains how social security and public education can be maintained with repeated voting also in the presence of productivity differences. It also finds that there can be multiple equilibria. If there are multiple equilibria, then a higher provision of public education is always associated with higher wage tax rate. This suggests that even if redistribution through social security system causes dead-weight loss, it might still improve efficiency by resulting in a more efficient provision of higher education.

The model economy has three overlapping generations of heterogeneous citizens. The young either study or work. The middle-aged work either as educated or uneducated labor. Part of potential tax revenue is lost due to a dead-weight loss from taxation, limiting taxation below a confiscatory level. The elderly are retirees. The wage tax revenue is used to finance both public education for the young and social security benefits to the retirees. The analysis is restricted to a linear taxation. ${ }^{1}$ Benefits are uniform, a simplification which captures the redistributive effects of social security. ${ }^{2}$

\footnotetext{
${ }^{1}$ Voting equilibrium may not be established by general non-linear taxation because of the possibility of Condorcet cycles.

${ }^{2}$ Miles and Timmermann (1999) report that the gross replacement rate was more than 10 percentage
} 
The citizens vote simultaneously on the wage tax rate and on the provision of public education. Voting on the wage tax rate and on the provision of public education captures competing uses of tax revenue, like that the elderly may benefit also from public health care, financed out of the same tax revenue as public education. If voting would take place simultaneously on social security benefits and public provision of education, then the elderly would be indifferent on the provision of education. Furthermore, if the vote would be only on expenditures and not on the tax rate then nothing would guarantee a priori that the government budget constraint would satisfy the resource constraint in the economy. With voting on the wage tax rate, this problem does not arise. The model assumes that all higher education is financed publicly. This is the case in several European OECD countries and a reasonable approximation also for others. ${ }^{3}$

The paper is organized as follows. Section 2 reviews the related literature. Section 3 presents the model. Section 4 is divided in two parts. The first part analyzes the economy when voting takes place with commitment to maintain the outcome during the lifetime of all voters. The second part generalizes all the results to an economy with repeated voting, and reports what type of implicit intergenerational contract solves time-consistency problem when voting is repeated. Section 5 concludes.

\section{Related Literature}

The interaction between social security and public education in the political process has received surprisingly little attention in the economics literature. Pogue and Sgontz (1977) already argued that the pay-as-you-go social security system provides a more powerful incentive for the current working age generations to invest in the human capital of younger generations compared to a fully-funded social security system. By giving current generation a stake in future production, it encourages the elderly to support such investments. Becker and Murphy (1988) suggest interpreting social security as intergenerational trade: children repay the public education they have received in old-age benefits. However, they do not study whether such arrangement would be sustainable in the political process, which is the focus of this paper. Konrad (1995) presents an overlapping generations model in which the old generation controls the political process. He argues that the old have an incentive to provide education and public infrastructure in order to increase social security tax revenue used to finance their benefits.

points higher for low-income workers in Belgium, Denmark, France, Greece, Ireland, Luxembourg, the Netherlands, Spain, Sweden and the United Kingdom in 1997.

${ }^{3}$ In seven countries all higher education is financed publicly. Private expenditures on higher education, net of public subsidies to private educational institutions, are 0.1 percent of GDP in five countries, 0.2 percent in four countries and 0.3 percent in the four countries with the highest share. Public expenditures on higher education range from 0.8 to 1.8 percent of GDP. (OECD 2004b) 
Rangel (2003) and Boldrin and Montes (2002) formalize public education and payas-you-go social security as two parts of an intergenerational contract. In their models, all voters inside each cohort are identical. To the best of my knowledge, there are no studies analyzing public education and social security arising from majority voting in the presence of ex ante visible productivity differences inside each cohort. The presence of productivity differences results in time-consistency problem on the part of high-productivity young citizens. They benefit from the implicit intergenerational contract as young but would prefer its collapse as middle-aged. This paper shows that the time-consistency problem can be solved by trigger strategies which do not punish upward deviations in the wage tax rate. The time-consistency problem is not present in the contributions by Rangel (2003) and Boldrin and Montes (2002) as they assume that all voters are identical.

When policy space is multidimensional and voters may have preferences which are not single-peaked, Condorcet winners need not exist. However, the political process always imposes some restrictions on decision-making. Shepsle (1979) shows that including the voting rules can generate a structure-induced equilibrium even when unrestricted voting would not result in a Condorcet winner. Building on earlier contributions by Shepsle (1979), Cooley and Soares (1999), Boldrin and Rustichini (2000) and Conde Ruiz and Galasso (2003), this paper identifies conditions under which public education and social security can be maintained, with repeated voting, by an implicit intergenerational contract relying on subgame perfect voting strategies without commitment. The solution concept with repeated voting is stationary subgame perfect structure-induced equilibrium, developed by Conde Ruiz and Galasso (2003). This notion combines structure-induced equilibrium in a voting system with commitment to an implicit intergenerational contract. ${ }^{4}$

The interaction between social security and public education has been analyzed also in several papers which assume that the two systems need not to have majority support. Kaganovich and Zilcha (1999) analyze how the allocation of tax revenues between public investment in education and social security benefits affects growth and welfare. Instead of analyzing voting, they solve the optimal government policy of dividing tax revenues between funding education and social security, such that steadystate growth is maximized. Kemnitz (2000) also assumes that the government chooses the social security tax rate that will finance old-age benefits and the tax rate that will finance public education for children.

\footnotetext{
${ }^{4} \mathrm{~A}$ related concept developed to study repeated majority voting is the notion of a Dynamic Condorcet Winner, developed by Bernheim and Nataraj (2002). They assume infinitely-lived agents. Using the same framework, Nataraj (2002) considers dividing a fixed surplus with overlapping generations. This paper is more general than Nataraj (2002) in endogenizing the surplus arising from public education and in allowing for ability differences, while Nataraj (2002) is more general in allowing for arbitrary divisions of the fixed pie between all cohorts.
} 


\section{The Model}

\subsection{The Citizens}

Individuals differ is two dimensions: age and productivity. There are three overlapping generations in each period: the young, the middle-aged and the elderly. There are two distinct career paths. Those who become educated study as young and work as middle-aged. Those who remain uneducated work both as young and as middle-aged. Both the educated and the uneducated are retired in the third period of their life. Education in this model corresponds to higher education, and it is provided publicly, as is the case in most European countries. The government has access to entrance examinations which allow it to screen applicants to the higher education. While not used in all countries, entrance examinations or results from baccalaureate or other tests are commonly used to select those who are admitted. The length of each period is one. The focus of the analysis is a small open economy, where the citizens can buy or sell assets in international financial markets at a given world interest rate normalized to zero. $^{5}$ There is no migration. Production technology is linear in both types of labor, so that issues of complementarity and substitutability do not arise.

The productivity in case of receiving higher education is denoted by variable $a$, labelled ability for simplicity. An educated citizen with ability a receives gross income $a$ as middle-aged. A citizen who remains uneducated receives a gross income of $u_{1}$ as young and a gross income of $u_{2}$ as middle-aged, independently of ability. The wage tax rate in period $t$ is denoted by $\tau_{t}$ and the lump-sum social security benefits are given by $b_{t}$. Preferences are given by a well-behaved utility function

$$
U=u\left(c_{i, t}^{y}, c_{i, t+1}^{m}, c_{i, t+2}^{o}\right),
$$

where $c_{i, t}^{y}$ is consumption as young, $c_{i, t+1}^{m}$ is consumption as middle-aged and $c_{i, t+2}^{o}$ is consumption as old for an individual $i$ who is young in period $t$. The individual lifetime budget constraint is for an individual $i$ young in period $t$ and remaining uneducated

$$
\begin{aligned}
c_{i, t}^{y} & =\left(1-\tau_{t}\right) u_{1}-s_{i, t}^{y}, \\
c_{i, t+1}^{m} & =\left(1-\tau_{t+1}\right) u_{2}+s_{i, t}^{y}-s_{i, t+1}^{m} \text { and } \\
c_{i, t+2}^{o} & =b_{t+2}+s_{i, t+1}^{m} .
\end{aligned}
$$

If the citizen with ability $a_{i}$ becomes educated, the budget constraint becomes

$$
\begin{aligned}
c_{i, t}^{y} & =-s_{i, t}^{y}, \\
c_{i, t+1}^{m} & =\left(1-\tau_{t+1}\right) a_{i}+s_{i, t}^{y}-s_{i, t+1}^{m} \text { and } \\
c_{i, t+2}^{o} & =b_{t+2}+s_{i, t+1}^{m} .
\end{aligned}
$$

\footnotetext{
${ }^{5} \mathrm{~A}$ previous version of this paper derived the results assuming a positive interest rate and allowing for population and productivity growth. The qualitative results are the same, but the analysis becomes more complicated.
} 
All individuals can save and borrow freely at the exogenous interest rate to smooth their consumption over their lifetime. Therefore, following the Fisher Separation Theorem, optimal individual choices can be characterized by a two-step optimization problem: one where individuals make their decisions on whether to receive education if this is offered and vote to maximize their net-of-tax lifetime income and a second one where, for a given lifetime income, individuals choose their utility-maximizing intertemporal consumption profile by borrowing and lending in the perfect capital market.

In each period, there are three overlapping generations, each of unit mass. Citizens are heterogeneous in their ability. The individual-specific ability variable follows in each period the same distribution in an interval, $a \in[0, \bar{a}) .{ }^{6}$ The density function of $a$ is $f(a)$ and its cumulative distribution function is $F(a)$.

\subsection{The Government's Budget Constraint}

The government's tax revenue in any given period depends on the educational status of the middle-aged cohort, on how many of the young are going to work and on any distortions associated with taxation. $L(\tau)$ denotes the share of tax revenue lost due to the dead-weight loss associated with taxation where the tax rate is $\tau$. For simplicity, the share of potential income lost is the same for each cohort. The wage tax revenue is a concave function of the wage tax rate and has a Laffer curve shape. Realized wage tax revenue is zero both with a wage tax rate of 0 and a wage tax rate of 1 , and there is a wage tax rate of $\widetilde{\tau}$, where $0<\widetilde{\tau}<1$, which maximizes the wage tax revenue. Formally,

$$
\begin{aligned}
L(0) & =L(1)=0, L^{\prime}(\tau) \geq 0, \text { and } \exists \widetilde{\tau}, 0<\widetilde{\tau}<1: \\
\frac{d}{d \tau}\{\tau[1-L(\tau)]\} & \geq 0 \text { when } \tau \leq \widetilde{\tau} \text { and } \\
\frac{d}{d \tau}\{\tau[1-L(\tau)]\} & \leq 0 \text { when } \tau \geq \widetilde{\tau} .
\end{aligned}
$$

Denote the ability threshold above which citizens became educated in period $t-1$ by $\widetilde{a}_{t-1}$, so that the current ability threshold is correspondingly $\widetilde{a}_{t} \cdot{ }^{7}$ The government's wage tax revenue is given by

\footnotetext{
${ }^{6}$ Assuming that there are no citizens with ability $\bar{a}$ simplifies the notation in the following section. Voting for an ability threshold $\bar{a}$ is there equivalent to voting for a zero provision of public education.

${ }^{7}$ This ability threshold is either the politically decided minimum ability required to enter the higher education or the minimum ability with which an individual would like to enter higher education, whichever is higher. The next section shows that in all equilibria, the politically decided minimum ability required to enter the higher education is higher than the minimum ability with which an individual would like to enter higher education.
} 


$$
\begin{aligned}
R_{t}\left(\widetilde{a}_{t-1}, \widetilde{a}_{t}, \tau_{t}\right)= & \tau_{t}\left[1-L\left(\tau_{t}\right)\right] F\left(\widetilde{a}_{t}\right) u_{1} \\
& +\tau_{t}\left[1-L\left(\tau_{t}\right)\right] F\left(\widetilde{a}_{t-1}\right) u_{2} \\
& +\tau_{t}\left[1-L\left(\tau_{t}\right)\right] \int_{a=\widetilde{a}_{t-1}}^{\bar{a}} a f(a) d a .
\end{aligned}
$$

The first term gives the tax revenue received from the young who remain uneducated, the second term gives the tax revenue from the middle-aged uneducated and the third term gives the tax revenue from the middle-aged educated.

In each period, the government uses its tax revenue for two purposes: financing public education and financing benefits for the elderly. The marginal cost of providing public education is constant $q$. Therefore, the cost of providing public education to the young above ability threshold $\widetilde{a}_{t}$ is in period $t$

$$
\left(1-F\left(\widetilde{a}_{t}\right)\right) q
$$

Social security benefits can be solved as a function of $\tau_{t}, \widetilde{a}_{t-1}$, and $\widetilde{a}_{t}$ :

$$
b_{t}\left(\widetilde{a}_{t-1}, \widetilde{a}_{t}, \tau_{t}\right)=R_{t}\left(\widetilde{a}_{t-1}, \widetilde{a}_{t}, \tau_{t}\right)-\left(1-F\left(\widetilde{a}_{t}\right)\right) q .
$$

Financing education from the tax revenue used to finance social security benefits instead of having separate tax rates for the two captures the idea of competing uses for the tax revenue. It is not required that $b_{t}>0$. If $\tau_{t}=0$ and education is publicly financed, $b_{t}$ would be negative by the government's budget constraint. However, it turns out that in equilibrium, $b_{t}$ is never negative. The first (second) argument of $b_{t}\left(\widetilde{a}_{t-1}, \widetilde{a}_{t}, \tau_{t}\right)$ refers to the ability threshold in period $t-1(t)$.

\section{Political Equilibria}

\subsection{Voting with Commitment}

This subsection analyzes simultaneous voting on the wage tax rate and public education when each generation assumes that the $\tau_{t}$ and $\widetilde{a}_{t}$ chosen will be in place over its whole lifetime. Therefore, there is commitment to maintaining the voting outcome for at least three periods. Assume that voting takes place once in three periods. The next subsection generalizes the results to the case in which voting takes place in each period. Studying voting first when each cohort votes only once during its lifetime allows to highlight the time-consistency problem arising from repeated voting without commitment.

When voting on the wage tax rate (the provision of education), citizens have to make a conjecture on the outcome of voting on the provision of education (the wage 
tax rate). With rational expectations, the outcome of the voting game validates these conjectures. Citizens vote in each policy dimension for their preferred alternative without abstention. ${ }^{8}$ Assuming a simultaneous majority vote on the two issues generates a structure-induced equilibrium:

Definition 1 A structure-induced equilibrium in voting with commitment to maintaining the voting outcome in period $t$ also in periods $t+1$ and $t+2 i s$, with a given provision of education in the previous period, $\widetilde{a}_{t-1}$, such a pair of $\widehat{a}_{t}$ and $\widehat{\tau}_{t}$ that:

(i) when citizens expect that the provision of education chosen will be $\widehat{a}_{t}$, $\widehat{\tau}_{t}$ is a Condorcet winner when voting on the wage tax rate

(ii) when citizens expect that the wage tax rate chosen will be $\widehat{\tau}_{t}, \widehat{a}_{t}$ is a Condorcet winner when voting on the provision of education.

With commitment, $\widehat{a}_{t+2}=\widehat{a}_{t+1}=\widehat{a}_{t}, \widehat{\tau}_{t+2}=\widehat{\tau}_{t+1}=\widehat{\tau}_{t}$. Then future social security benefits are given by ${ }^{9}$

$$
b_{t+1}=b_{t+2}\left(\widehat{a}_{t}, \widehat{a}_{t}, \widehat{\tau}_{t}\right) .
$$

The same value of $\widetilde{a}_{t}$ which maximizes social security benefits with a given $\tau_{t}$ in the following period, maximizes social security benefits with the same $\tau_{t}$ in period $t+2$. For the old voting in period $t$, however, social security benefits are given by

$$
b_{t}\left(\widetilde{a}_{t-1}, \widehat{a}_{t}, \widehat{\tau}_{t}\right)=R_{t}\left(\widetilde{a}_{t-1}, \widehat{a}_{t}, \widehat{\tau}_{t}\right)-\left(1-F\left(\widehat{a}_{t}\right)\right) q .
$$

It is worth emphasizing the double role of individuals. As citizens, they vote for the $\tau$ and $\widetilde{a}$ they would prefer, given the conjecture they make on the equilibrium in voting in the other dimension. As consumer-producers, they take the voting outcome as given. The citizens vote in order to maximize the net present value of their current and future incomes. With perfect capital markets, this maximizes their utility by Fisher's Separation Theorem. Denote the value of the sum of the current and future income after taxes and transfers for a citizen of age $k, k$ being $y$ for the young, $m$ for the middle-aged and $o$ for the old, by $V^{k}$. For the young citizens, $V^{y}$ depends on the

\footnotetext{
${ }^{8}$ This assumption is made also by Cooley and Soares (1999) who analyze voting on whether to maintain the social security system. As citizens of measure zero would not have an economic incentive to vote with any positive voting cost if voting does not generate any other benefit in addition to its expected effect on the policy adopted, sincere voting has to be assumed. This does not seem a too restrictive assumption, as citizens cannot gain by misrepresenting their preferences. Sincere voting weakly dominates other voting strategies when voting is costless, as it would result in the better outcome than any other voting strategy if the individual's vote would be decisive and would not result in a worse outcome if this were not the case.

${ }^{9} \mathrm{~A}$ "hat" denotes the equilibrium outcome of a variable, while $\tau_{t}$ and $\widetilde{a}_{t}$ denote any possible values for the wage tax rate and the ability threshold above which citizens receive higher education. In period $t, \widehat{a}_{t}$ and $\widehat{\tau}_{t}$ refer to the expected equilibrium outcomes arising from the political process, while $\widetilde{a}_{t-1}$ is the threshold ability level that was in place in the previous period.
} 
individual's own ability $a$, the provision of education $\widetilde{a}_{t}$ and the wage tax rate $\tau_{t}$. In case of becoming educated, $V_{t}^{y}$ is given by

$$
V_{t}^{y}\left(a, \widetilde{a}_{t}, \tau_{t}\right)=\left(1-\tau_{t}\right) a+b_{t+2}\left(\widetilde{a}_{t}, \widetilde{a}_{t}, \tau_{t}\right)
$$

whereas for those who remain uneducated, it is:

$$
V_{t}^{y}\left(a, \widetilde{a}_{t}, \tau_{t}\right)=\left(1-\tau_{t}\right) u_{1}+\left(1-\tau_{t}\right) u_{2}+b_{t+2}\left(\widetilde{a}_{t}, \widetilde{a}_{t}, \tau_{t}\right) .
$$

The first argument in $V_{t}^{y}\left(a, \widetilde{a}_{t}, \tau_{t}\right)$ is the individual ability, the second argument is the ability threshold and the third argument is the wage tax rate. The preferred provision of education and wage tax rate for a young citizen with ability $a$ are given by

$$
\begin{aligned}
\widetilde{a}_{t}^{*}\left(\widehat{\tau}_{t}\right) & =\arg \max _{\widetilde{a}_{t} \in[0, \bar{a}]} V_{t}^{y}\left(a, \widetilde{a}_{t}, \widehat{\tau}_{t}\right) \\
\tau_{t}^{*}\left(\widehat{a}_{t}\right) & =\arg \max _{\tau_{t} \in[0,1]} V_{t}^{y}\left(a, \widehat{a}_{t}, \tau_{t}\right) .
\end{aligned}
$$

These reaction functions specify the preferred choice in one dimension conditional on the equilibrium outcome in the other dimension.

For the middle-aged, $V_{t}^{m}$ is given by

$$
\begin{aligned}
V_{t}^{m} & =\left(1-\tau_{t}\right) u_{2}+b_{t+1}\left(\widetilde{a}_{t}, \widetilde{a}_{t}, \tau_{t}\right) \text { for those with } a<\widetilde{a}_{t-1} \\
V_{t}^{m} & =\left(1-\tau_{t}\right) a+b_{t+1}\left(\widetilde{a}_{t}, \widetilde{a}_{t}, \tau_{t}\right) \text { for those with } a \geq \widetilde{a}_{t-1}
\end{aligned}
$$

The preferred provision of education and wage tax rate for a middle-aged citizen with ability $a$ are given by

$$
\begin{aligned}
\widetilde{a}_{t}^{*}\left(\widehat{\tau}_{t}\right) & =\arg \max _{\widetilde{a}_{t} \in[0, \bar{a}]} V_{t}^{m}\left(a, \widetilde{a}_{t-1}, \widetilde{a}_{t}, \widehat{\tau}_{t}\right) \\
\tau_{t}^{*}\left(\widehat{q}_{t}\right) & =\arg \max _{\tau_{t} \in[0,1]} V_{t}^{m}\left(a, \widetilde{a}_{t-1}, \widehat{a}_{t}, \tau_{t}\right) .
\end{aligned}
$$

The presence of the term $\widetilde{a}_{t-1}$ captures the effect of past education policy on the current political preferences. Middle-aged citizens with $a<\widetilde{a}_{t-1}\left(a \geq \widetilde{a}_{t-1}\right)$ are uneducated (educated). Nonetheless, the optimal provision of education preferred by the middle-aged is, independently of whether they are educated or not, such that solving $\arg \max _{\widetilde{a}_{t} \in[0, \bar{a}]} b_{t+1}$. This results as the only motivation for the middle-aged to support public education is to increase their future retirement benefits.

The value function of public policies for the elderly is given by

$$
V_{t}^{o}\left(a, \widetilde{a}_{t-1}, \widetilde{a}_{t}, \tau_{t}\right)=R_{t}\left(\widetilde{a}_{t-1}, \widetilde{a}_{t}, \tau_{t}\right)-\left(1-F\left(\widetilde{a}_{t}\right)\right) q .
$$

Therefore, the preferred provision of education and wage tax rate for any old citizen are given by

$$
\begin{aligned}
\widetilde{a}_{t}^{*}\left(\widehat{\tau}_{t}\right) & =\arg \max _{\widetilde{a}_{t} \in[0, \bar{a}]} V_{t}^{o}\left(a, \widetilde{a}_{t-1}, \widetilde{a}_{t}, \tau_{t}\right) \\
\tau_{t}^{*}\left(\widehat{a}_{t}\right) & =\arg \max _{\tau_{t} \in[0,1]} V_{t}^{o}\left(a, \widetilde{a}_{t-1}, \widetilde{a}_{t}, \tau_{t}\right) .
\end{aligned}
$$


The elderly oppose any provision of public education, thereby voting for $\widetilde{a}_{t}=\bar{a}$. They lose from public education both directly as the financing of public education competes for the same tax revenue as social security benefits, and indirectly as more public education implies that a greater part of the young do not work. All the benefits from public education accrue only after the old have died. Even though the young have non-monotonic preferences concerning the provision of public education, it is possible to establish that:

Lemma 1 In any structure-induced equilibrium, the provision of education is chosen in order to maximize the future social security benefits, and is given by

$$
\widehat{a}_{t}=u_{1}+u_{2}+\frac{q}{\widehat{\tau}_{t}\left[1-L\left(\widehat{\tau}_{t}\right)\right]} .
$$

All citizens with $a \geq \widehat{a}_{t}$ strictly prefer to receive public education, rather than remain uneducated.

Proof. Proof is given in the Appendix.

Lemma 1 proves that the participation constraint for citizens having to be willing to receive higher education if it is offered them is never binding in an equilibrium.

We can next derive

Lemma 2 In any structure induced equilibrium $\left(\widehat{a}_{t}, \widehat{\tau}_{t}\right)$, the wage tax rate $\widehat{\tau}_{t}$ is that preferred, under conjecture $\widetilde{a}_{t}=\widehat{a}_{t}$, by the citizen with the median net present value of remaining lifetime wage income.

Proof. Proof is given in the Appendix.

Lemma 2 implies that the middle-aged uneducated prefer higher taxes than the young uneducated. As the young uneducated have a lower lifetime income than the educated with the lowest income, as shown in the proof of Lemma 1, the young uneducated vote for higher taxes than any of the educated. Furthermore, those young to be educated and those middle-aged who are already educated vote for the same wage tax rate, if they have the same abilities.

The existence of a structure-induced equilibrium with a voting with commitment does not guarantee that repeating voting in period $t+3$ would produce the same outcome. In other words, it is conceivable that some ability distributions would result in voting cycles. If voting in period $t+3$ would result in the same outcome as voting in period $t$, then the voting outcome in period $t$ is a steady-state outcome: once the economy is in it, repeated voting every three periods perpetuates this outcome. Define

Definition 2 A combination of $\left(\widehat{a}_{t}, \widehat{\tau}_{t}\right)$ is a steady-state structure-induced equilibrium (SSSIE) if it is a structure-induced equilibrium when $\widetilde{a}_{t-1}=\widehat{a}_{t}$. 
This definition is written for the initial condition $\widetilde{a}_{t-1}$ rather than for the voting outcome in period $t+3$ to highlight that a steady-state outcome arises if the ability threshold associated with this outcome is a fixed point in the political process. In other words, a steady-state structure-induced equilibrium is such that voting results in the same ability threshold as was the initial condition when the voting took place. Note that if voting outcome $\left(\widehat{a}_{t}, \widehat{\tau}_{t}\right)$ is a steady-state structure-induced equilibrium from period $t$ onwards, it is so also from period $t-1$ onwards.

In a SSSIE the outcome of the voting would not change even if the ballot were unexpectedly repeated already before the third period after the previous vote. ${ }^{10}$ Whether there is a SSSIE depends on the distribution of $a$, as well as on $u_{1}, u_{2}, q$ and $L(\tau)$. The possible SSSIE are given by

Proposition 1 If $\left(\widehat{a}_{t}, \widehat{\tau}_{t}\right)$ is a steady-state structure-induced equilibrium, then the median voter on both $a_{t}$ and $\tau_{t}$ is, with $\widetilde{a}_{t-1}=\widehat{a}_{t}$,

(i) a middle-aged uneducated citizen if $F\left(\widehat{a}_{t}\right) \geq \frac{1}{2}$;

(ii) a young citizen who remains uneducated if $\frac{1}{4} \leq F\left(\widehat{a}_{t}\right)<\frac{1}{2}$;

(iii) a young citizen who becomes educated and a middle-aged educated citizen whose ability $a_{i i i}$ is given by $F\left(a_{i i i}\right)=\frac{1}{4}$ if $F\left(\widehat{a}_{t}\right)<\frac{1}{4}$.

Proof. Proof is given in the Appendix.

Proposition 1 implies

Corollary 1 Even with three cohorts of the same size, the median voter may be a young citizen.

Proposition 1 does not exclude a possibility of multiple equilibria. Whether there are multiple equilibria or not depends on the distribution of ability, and on $u_{1}, u_{2}, q$ and $L(\tau)$ :

Proposition 2 There may but need not be multiple equilibria.

Proof. Proof is given in the Appendix.

Proposition 2 demonstrates that a given ability distribution may support different equilibria, depending on initial conditions. Even when there are multiple equilibria, it is possible to establish a relative ranking of tax rates and public provision of education in these:

Proposition 3 If there are two steady-state structure-induced equilibria $\left(\widehat{a}_{t}^{1}, \widehat{\tau}_{t}^{1}\right)$ and $\left(\widehat{a}_{t}^{2}, \widehat{\tau}_{t}^{2}\right)$, then $\widehat{\tau}_{t}^{1}>\widehat{\tau}_{t}^{2}$ implies $\widehat{a}_{t}^{1}<\widehat{a}_{t}^{2}$.

\footnotetext{
${ }^{10}$ Note that the policy conclusions do not rely on the assumption that voting would take place only once in every three periods. These are just simplifying steps to derive the results with repeated voting in the following subsection.
} 
Proof. Notice that the political process leads always into a tax rate which is on the upward-sloping part of the Laffer curve, as the elderly prefer the value at the top and the younger voters, including the median voter, a lower value. Therefore, $\widehat{\tau}_{t}^{1}>\widehat{\tau}_{t}^{2}$ implies

$$
\widehat{\tau}_{t}^{1}\left[1-L\left(\widehat{\tau}_{t}^{1}\right)\right]>\widehat{\tau}_{t}^{2}\left[1-L\left(\widehat{\tau}_{t}^{2}\right)\right] .
$$

By (3) this implies that $\widehat{a}_{t}^{1}<\widehat{a}_{t}^{2}$.

The result of Proposition 3 is intuitive: As public education receives majority support only when it increases the social security benefits, the number of students educated is increasing in the public stake in returns to education.

\subsection{Repeated Voting}

This subsection analyzes an economy in which voting on $\widetilde{a}$ and $\tau$ takes place in every period. The equilibrium is now maintained by an implicit intergenerational contract supported by a suitable trigger strategy, instead of by commitment.

Conde Ruiz and Galasso (2003) introduce the notion of a stationary subgame perfect structure induced equilibrium. ${ }^{11}$ They apply subgame perfection to the notion of a structure-induced equilibrium introduced by Shepsle (1979). Agents vote according to a stationary subgame perfect strategy profile. A strategy for an individual is a mapping from the history of the voting outcomes to the wage tax rate $\tau_{t}$ and the provision of public education $\widetilde{a}_{t}$ that the individual votes for, and is subject to $\tau_{t} \in[0,1]$ and $\widetilde{a}_{t} \in[0, \bar{a}]$. Let $s_{t}^{k}$ be the voting strategy profile over $\tau_{t}$ and $\widetilde{a}_{t}$ of all individuals belonging to generation $k$ in period $t$. Here $k$ can be either $y$ (young), $m$ (middle-aged) or $o$ (old). As the realized income of the middle-aged depends on the provision of education in the previous period, their voting strategy is denoted by $s_{t}^{k}\left(\widetilde{a}_{t-1}\right)$ to make explicit that their voting strategy in period $t$ depends on the provision of education in period $t-1$. Denote the first period when the game is played and when the equilibrium strategy may be established, with the education of the middle-aged corresponding to the long-run equilibrium, by 0 . The history of the game at period $t, h_{t}$, reports those combinations of $\widetilde{a}$ and $\tau$ chosen in all previous periods starting from $t=0$ : $h_{t}=\left\{\left(\widetilde{a}_{0}, \tau_{0}\right),\left(\widetilde{a}_{1}, \tau_{1}\right), \ldots,\left(\widetilde{a}_{t-2}, \tau_{t-2}\right),\left(\widetilde{a}_{t-1}, \tau_{t-1}\right)\right\}$ when $t>0$. The set of all possible past outcomes at time $t$ is denoted by $H_{t}$. The following formal definition is taken, with slight modifications, from Conde Ruiz and Galasso (2003):

Definition 3 A voting strategy profile $s=\left\{\left(s_{t}^{y} \cup s_{t}^{m} \cup s_{t}^{o}\right)\right\}_{t=0}^{\infty}$ is a stationary subgame perfect structure-induced equilibrium (SSPSIE), if the following conditions are satisfied:

(i) $s$ is a subgame perfect equilibrium.

\footnotetext{
${ }^{11}$ Conde Ruiz and Galasso analyze simultaneous voting on the tax rate and early retirement provisions. They restrict the decision on early retirement provisions to a binary choice between full benefits or no benefits at all, whereas this paper analyzes a two-dimensional policy space with a continuum of alternatives in both dimensions.
} 
(ii) At every period t, the equilibrium outcome associated with $s$ is a structureinduced equilibrium of the static game with commitment.

(iii) In any period and for any history, $h_{t} \in H_{t}$, the sequence of equilibrium outcomes induced by $s$ is constant.

Conde Ruiz and Galasso (2003) assume a trigger strategy, specifying that the voting outcome converges to a complete abolition of the social security system in the case of the result in one period differing from the subgame perfect equilibrium with a once-andfor-all voting. In an intergenerational game with public provision of education, such a threat strategy would not always maintain the subgame perfect structure-induced equilibrium, resulting from voting with commitment, when there is instead repeated voting. The reason for this is that the high-ability young citizens with higher than average income would like to have wage taxation eliminated after they have completed their education.

With a threat strategy demanding a zero wage taxation following any deviation, the young expecting to pay more in taxes than they receive back in social security benefits may find it optimal to deviate. When voting with commitment, they would prefer a lower wage tax rate than the median voter. By voting for a higher wage tax rate than the median voter, they would change the identity of the median voter in regime (iii) of Proposition 1. In this way, they would cause an upward deviation in wage taxation during their youth when they do not pay taxes, triggering an elimination of public expenditures in the following period when they would otherwise pay taxes. Thus, the trigger strategy by Conde Ruiz and Galasso would not allow maintaining social security and public education with repeated voting. This results from the timeconsistency problem that the high-ability young citizens face. However, there is a trigger strategy which allows the outcome of voting with commitment to be maintained also with repeated voting. This is:

Definition 4 In the implicit intergenerational contract voting strategy (IICVS) related to an equilibrium $(\widehat{a}, \widehat{\tau})$, a citizen $i$, who prefers $\widetilde{a}_{t}^{i}(\widehat{\tau})$ and $\tau_{t}^{i}(\widehat{a})$ when voting with commitment, votes for this provision of education and wage tax rate in period $t=0$, as well as in period $t>0$, provided that the history for the previous periods satisfies $\widetilde{a}_{j}=\widehat{a} \forall j \in\{0,1, \ldots, t-1\}$ and $\tau_{j} \geq \widehat{\tau} \forall j \in\{0,1, \ldots, t-1\}$. If these conditions are not satisfied, the citizen votes for the $\tau_{t}$ and $\widetilde{a}_{t}$ he or she preferred in period $t$, assuming that the (other) young and middle-aged citizens no longer vote for a positive wage tax rate due to the collapse of the implicit intergenerational contract. The individual-specific superscript $i$ captures both age and ability.

IICVS states that any other deviation from the intergenerational contract except for a deviation to a higher wage tax rate leads to the break-down of the intergenerational contract. Once the trust in the maintenance of the intergenerational transfer 
institutions is lost, they will collapse. If voting in some period would produce a higher wage tax rate than in the equilibrium, then the IICVS specifies that this does not violate the contract. Neither does it give a reason for changing the $\widetilde{a}$ and $\tau$ specified by the contract. Intuitively, working generations are not punished by an abolition of future social security if their voting would lead to paying higher social security benefits than specified by the contract. ${ }^{12}$ This strategy supports a SSSIE also with repeated voting:

Proposition 4 Any steady-state structure-induced equilibrium which would exist when voting with commitment can be maintained also in repeated voting as a stationary subgame perfect structure-induced equilibrium.

Proof. Proof is given in the Appendix.

Proposition 4 shows that all results derived in the previous subsection for a steadystate structure-induced equilibrium hold also when voting is repeated in each period. Therefore, any implicit intergenerational contract on public education and social security benefits which could be implemented with commitment can be maintained also with repeated voting. A suitably formulated trigger strategy solves the time-consistency problem on the part of the high-income young citizens. Repeated voting may sustain multiple equilibria, characterized in Proposition 1. As Proposition 3 reports, equilibria associated with higher tax rates are also associated with a wider provision of public education.

\section{Conclusion}

This paper has analyzed simultaneous voting on the wage tax rate and investment in public education in a "European" economy in which the private cost of education is limited to the opportunity cost of lost wage income. The part of the tax revenue which is not used to finance public education is distributed to the old as social security benefits. When voting, citizens choose an optimal policy in each dimension, the wage tax rate and the provision of public education, subject to a conjecture of the outcome in the other dimension. This paper generalizes the results from previous literature, most notably Rangel (2003) and Boldrin and Montes (2002), by allowing productivity differences inside each cohort.

\footnotetext{
${ }^{12}$ An alternative trigger strategy would specify that all agents vote for $\widetilde{a}=\bar{a}$ and $\tau=0$ if the contract has been violated in the previous period. While this would lead to the same outcome as the IICVS, voting for $\widetilde{a}=\bar{a}$ is weakly dominated by voting for any $\widetilde{a} \in\left[0, a^{i}\right]$ for the young with $a^{i}>u_{1}+u_{2}$. Likewise, for the old voting for $\tau=0$ is weakly dominated by voting for the rate of $\tau$ which maximizes the wage tax revenue for the social security benefits. With IICVS, no citizen votes for a weakly dominated strategy.
} 
Productivity differences introduce time-consistency problem in the presence of repeated voting. The high-productivity young citizens benefit from the implicit intergenerational contract that links public education and social security benefits and would vote in its favor in case of voting with commitment to maintain the system in place for their whole lifetime. If voting is repeated, however, they would prefer the implicit contract to collapse after receiving their education. This can be avoided by a trigger strategy which punishes any deviations from the equilibrium public provision of education, and punishes also downward deviations from the equilibrium wage tax rate. A key mechanism to solve the time-consistency problem is that the implicit intergenerational contract specifies that upward deviations in the wage tax rate are not punished. The presence of productivity differences also implies that the median voter may be young, even when the three generations are of the same size.

The basic model presented in this paper could be extended in several ways. Assuming a positive interest rate and population growth rate would leave propositions 2, 3 and 4 unchanged. Naturally, population growth rate would change the ability thresholds resulting in different equilibria in proposition 1. A more substantive change would be to introduce uncertainty on the lifetime or on realized income, or to allow parents to have altruistic motivations towards their children. Another topic for further research would be to develop a computational general equilibrium model and use that to estimate the political equilibria that the model would predict in different countries. This would allow testing the theory empirically. Running simple correlations between wage taxation and expenditures on public education as a share of GDP does not allow testing the theory, as it does not take into account country-specific differences in the productivity of labor or productivity distribution. Furthermore, it would be desirable to allow for a possibility that labor supplied by the educated and that supplied by the uneducated could be complements in production. These and other possible extensions are left for future research.

The interaction between voting on income redistribution without commitment and human capital formation has been recently analyzed also by Hassler et al. (2003). They provide an analytical characterization of Markov perfect equilibria with repeated voting on one issue, namely distortionary income redistribution. In their model, individuals are ex ante identical and they invest privately in education. This paper follows Cooley and Soares (1999), Boldrin and Rustichini (2000), and Conde Ruiz and Galasso (2003) by assuming that an implicit intergenerational contract is supported by a trigger strategy. If the model would be solved restricting attention to Markovian strategies, the analysis would suggest that social security and public education could not be maintained. To see this, note that Markovian voting strategies allow the current policy choice to depend only on a state variable, and not on the entire history of outcomes. In the current framework, the state variable would be the education provided in the previous period. In the absence of an implicit intergenerational contract supported by a trigger strategy this would give the young and the middle-aged incentives to vote against social security, the collapse of which would also lead into the collapse of 
the provision of public education. The persistence of social security system and public provision of education in European countries can, therefore, be interpreted as an indirect evidence on the importance of reputational mechanisms in intergenerational decision-making.

\section{Appendix}

\section{Proof of Lemma 1.}

With any given conjecture of $\widehat{\tau}_{t}$ on the wage tax rate, the middle-aged vote for the provision of education that maximizes social security benefits in future periods, and the old vote for zero provision of public education (maximum threshold level). To see that the young never vote for a higher threshold level than the middle-aged note that if they did, they could always increase their lifetime income by switching to the provision of education that maximizes social security benefits in future periods. Differentiating $b_{t+1}\left(\widehat{a}_{t}, \widehat{a}_{t}, \widehat{\tau}_{t}\right)$ with respect to $\widehat{a}_{t}$ yields

$$
\widehat{\tau}_{t}\left[1-L\left(\widehat{\tau}_{t}\right)\right] f\left(\widehat{a}_{t}\right)\left(u_{1}+u_{2}-\widehat{a}_{t}\right)+q f\left(\widehat{a}_{t}\right)=0,
$$

giving the claimed result. An individual with ability $a$ is willing to receive higher education if and only if this results in higher after-tax income, that is

$$
\left(1-\widehat{\tau}_{t}\right) a \geq\left(1-\widehat{\tau}_{t}\right)\left(u_{1}+u_{2}\right) .
$$

As any $a$ higher than (or equal to) $\widehat{a}_{t}$ implied by (3) satisfies (4), all citizens for whom public education is available prefer to receive it. Finally, note that a young voter for whom $a=\widehat{a}_{t}-\varepsilon$ votes for his or her ability level as ability threshold, provided that $\varepsilon$ is sufficiently small, as $a$ implied by (4) is strictly smaller than $\widehat{a}_{t}$ implied by (3) when $q>0$.

\section{Proof of Lemma 2.}

The marginal benefit from $\tau_{t}$ is for all citizens equal to the increase in their social security benefits, while the marginal cost is the net present value of the increase in their remaining tax payments. The elderly prefer the tax rate maximizing the wage tax revenue. The marginal benefit from an increase in the wage tax is the same for all the young and the middle-aged by $V_{t}^{y}, V_{t}^{m}$ and (2), while the marginal cost is equal to their remaining lifetime gross wage income. By the concavity of $b_{t}$, the preferred tax rate is decreasing in the remaining lifetime gross wage income, guaranteeing the existence and the identity of the median voter as claimed.

\section{Proof of Proposition 1.}

As the provision of education chosen is given by Lemma 1 and is that preferred by the claimed median voter in each regime, it suffices to analyze voting on the wage tax rate. As $\widehat{a}_{t}>u_{1}+u_{2}$ in any equilibrium by (3), the middle-aged uneducated prefer higher taxes than the young uneducated, and these prefer higher taxes than anyone who is going to become educated. Furthermore, the preferred tax rate of the educated is declining in their ability and is the same whether they are young or middle-aged. With mass of each cohort normalized to unity, note that in scenario (i) the elderly and the 
middle-aged uneducated alone form more than half of the population. In scenario (ii), the elderly and the middle-aged uneducated alone are not enough to form a majority in this case. Together with the young uneducated, they form the majority. In scenario (iii), the elderly and the uneducated are not alone in majority. As the young to be educated and the middle-aged educated prefer the same tax rate with the same ability, the median voter is a citizen with ability $a_{i i i}$, whether young or middle-aged.

\section{Proof of Proposition 2.}

In each tentative equilibrium, the equilibrium tax rate can be solved given the assumption on the provision of education. This tentative equilibrium tax rate can then be inserted into (3) to verify whether the associated ability threshold is consistent with the initial assumption on who becomes educated. Assume first that 30 percent of population have $a=1.7,40$ percent have $a=1.5$ and 30 percent have $a=0.8$, and that $u_{1}=0.1, u_{2}=0.8, q=0.08$, and $L\left(\tau_{t}\right)=\tau_{t}$. There are three SSSIE. In the first one, both citizens with ability level 1.7 and those with ability level 1.5 receive education, and $\tau_{t}=0.17$. In the second one, only citizens with ability level 1.7 receive education, and $\tau_{t}=0.15$. In the third equilibrium, no citizen receives education, and $\tau_{t}=0.056$. In the first equilibrium, the median voter is a young citizen who remains uneducated, and in the second and third equilibria, a middle-aged uneducated. Assume next that 30 percent of population have $a=2,40$ percent have $a=1.8$ and 30 percent have $a=0.8$, and that $u_{1}=0.5, u_{2}=0.5, q=0.05$, and $L\left(\tau_{t}\right)=\tau_{t}$. Now the only equilibrium which exists is the one in which citizens with $a=2$ and $a=1.8$ become educated. Inserting the tentative equilibrium tax rate associated with the other equilibria into (3) shows that the associated ability threshold violates the initial assumption on who becomes educated.

\section{Proof of Proposition 4.}

Assume that $(\widehat{a}, \widehat{\tau})$ is a SSSIE with voting with commitment. It is sufficient to prove that with IICVS, the citizens either do not want to deviate or if they would like to deviate, then their deviation does not change the outcome of the voting in a way that would result in the collapse of the intergenerational contract. The elderly have clearly no interest in deviating from voting for the $\tau$ and $\widetilde{a}$ which would maximize their current social security benefits. Neither do the middle-aged have any incentive to deviate from the $\tau$ and $\widetilde{a}$ they would prefer with commitment. A deviation downward in the wage tax rate or the provision of education would only result in them losing their social security benefits in the following period. The young uneducated, on the other hand, already vote for the $\widetilde{a}$ and $\tau$ that would maximize their lifetime utility, so they have no incentive to deviate. As for the young citizens who are going to become educated, they are in any case in minority when voting on the provision of education, so any deviation in that dimension by them would have no effect on the voting outcome. When voting on the wage tax rate, the young who are going to lose from income redistribution would prefer to have the wage taxation and public provision of education abolished in future. However, they are already voting for a lower wage tax rate than the median voter, so that any deviation downward would not affect the 
outcome of the voting. The only way in which the young who prefer a lower wage tax rate than that preferred by the median voter can change the outcome of voting is by voting for a higher wage tax rate than that preferred by the median voter. By the definition of IICVS, a deviation upward would not cause the abolition of wage taxation and public provision of education. Therefore, the young who will become educated cannot gain anything by deviating from voting for their preferred wage tax rate with voting with commitment. The threat point of the voting equilibrium $(\bar{a}, 0)$ following a punishable deviation is also a subgame perfect Nash-equilibrium. If the young and the middle-aged expect that social security benefits will not be maintained in future, they have no interest in maintaining them after a deviation. This implies that the middle-aged would join the old in opposing any investment in public education. The old would still vote for $\tau>0$ and the young whose ability exceeds $u_{1}+u_{2}$ for $\widetilde{a}<\bar{a}$, but both are in minority.

\section{References}

[1] Becker, G., Murphy, K., 1988. The family and the state. Journal of Law and Economics 31, 1-18.

[2] Bernheim, B.D., Nataraj, S., 2002. A solution concept for dynamic problems in political economy. Manuscript. Stanford University.

[3] Boldrin, M., Montes, A., 2002. The intergenerational state. Education and pensions. Manuscript. University of Minnesota, Department of Economics.

[4] Boldrin, M., Rustichini, A., 2000. Political equilibria with social security. Review of Economic Dynamics 3, 41-78.

[5] Conde Ruiz, J.I., Galasso, V., 2003. Early retirement. Review of Economic Dynamics $6,12-36$.

[6] Cooley, T.F., Soares, J., 1999. A positive theory of social security based on reputation. Journal of Political Economy 107, 135-160.

[7] Hassler, J., Rodríguez Mora, J.V., Storesletten, K., Zilibotti, F., 2003. The survival of the welfare state. American Economic Review 93, 87-112.

[8] Kaganovich, M., Zilcha, I., 1999. Education, social security, and growth. Journal of Public Economics 71, 289-309.

[9] Kemnitz, A., 2000. Social security, public education, and growth in a representative democracy. Journal of Population Economics 13, 443-462.

[10] Konrad, K.A., 1995. Social security and strategic inter-vivos transfers of social capital. Journal of Population Economics 8, 315-326. 
[11] Miles, D., Timmermann, A., 1999. Risk sharing and transition costs in the reform of pension systems in Europe. Economic Policy 14, 251-286.

[12] Nataraj, S., 2002. Age bias in fiscal policy: Why does the political process favor the elderly? Manuscript. Occidental College.

[13] OECD, 2004a. Social Expenditure Database. SOCX, http://www.oecd.org/els/social/expenditure.

[14] OECD, 2004b. Expenditure on Educational Institutions Relative to Gross Domestic Product, http://www.oecd.org/dataoecd/62/21/33670978.xls

[15] Pogue, T.F., Sgontz, L.G., 1977. Social security and investment in human capital. National Tax Journal 30, 157-169.

[16] Rangel, A., 2003. Forward and backward intergenerational goods: Why is social security good for the environment? American Economic Review 93, 813-834.

[17] Shepsle, K.A., 1979. Institutional arrangements and equilibrium in multidimensional voting models. American Journal of Political Science 23, 27-59. 